\title{
Minireviews
}

\section{Factors Contributing to the Antiviral Effectiveness of Tenofovir}

\author{
Rachel A. Murphy and Monica A. Valentovic \\ Department of Biomedical Sciences, Toxicology Research Cluster, Joan C. Edwards School of Medicine, Marshall University, \\ Huntington, West Virginia (R.A.M., M.A.V.)
}

Received May 30, 2017; accepted August 25, 2017

\begin{abstract}
Over 1 million people in the United States are living with human immunodeficiency virus (HIV), which may progress to AIDS. The use of antiviral therapy has successfully controlled the rate of viral growth in patients. Antiviral agents improve the quality of life and reduce the potential for spreading HIV; HIV is currently considered a chronic disease provided patients are compliant with their antiviral medications. Tenofovir is a nucleoside transcriptase inhibitor that prevents viral replication and is approved for treatment of HIV and chronic hepatitis B infection. Tenofovir is an antiretroviral drug used alone and in combination with other nucleoside reversetranscriptase inhibitor agents to lower viral load in HIV patients. Tenofovir is administered as a prodrug to increase bioavailability. The prodrug forms of tenofovir are tenofovir
\end{abstract}

disoproxil fumarate, approved in 2001, and tenofovir alafenamide, approved in 2016. Tenofovir is extensively used in controlling HIV, as it is administered once daily, allowing for good compliance. This minireview discusses the impact of food, age, and drug transporters on tenofovir absorption and clearance. The changes in dosing that are needed in the presence of renal impairment, which is a common occurrence with HIV chronic disease progression, will also be discussed. The potential special conditions occurring with fixed-combination doses containing tenofovir will also be reviewed, including the use of cobicistat, a cytochrome P450 3A4 inhibitor. The short review also addresses some newer preparations using niosomes to improve tenofovir absorption and delivery to the target cells.

\section{Introduction}

Human immunodeficiency virus (HIV) is a virus that decimates the immune system. HIV targets a specific type of white blood cells known as T cells, T lymphocytes, or CD4 cells. A decline in CD4 cell count mediated by HIV leaves the body open to opportunistic infections. At one time, HIV rapidly progressed to AIDS and death, but advancements in highly active antiretroviral therapy have made HIV a chronic condition rather than a death sentence. Tenofovir (TFV), formerly known as 9-(R)(2-phosphonomethoxypropyl)adenine, is a reverse-transcriptase inhibitor that has potent and selective inhibition of HIV and herpes viruses' reverse transcriptase. TFV is an acyclic nucleotide analog of adenosine $5^{\prime}$ monophosphate that is phosphorylated intracellularly by adenylate kinase to its active form, TFV diphosphate (Fig. 1). TFV is effective in cases of nucleosideresistant HIV infection, making it a first-line agent for treatment of this disease (Miller et al., 2001; Squires et al., 2003).

Despite its efficacy, poor bioavailability was a limiting factor in development of TFV as a clinical agent. Oral administration

https://doi.org/10.1124/jpet.117.243139. of TFV had $18 \%$ bioavailability in beagles and $5.3 \%$ in monkeys (Shaw et al., 1997; Cundy et al., 1998). Research efforts subsequently focused to improve bioavailability by altering TFV formulation but maintain antiviral activity. Two methyl carbonate esters were added to form the prodrug TFV disoproxil fumarate (TDF), which demonstrated equivalent antiviral activity with bioavailability increased to $30.1 \%$ in beagles and $25 \%$ in humans (Shaw et al., 1997; Barditch-Crovo et al., 2001). TDF was approved in fall 2001 by the United States Food and Drug Administration (FDA) to treat chronic hepatitis B and HIV in conjunction with other agents (Gilead Sciences, 2001). There are several factors that alter TDF bioavailability and pharmacokinetics, including age, sex, and food intake. This article provides a review of TFV bioavailability as well as factors that have an impact on TFV pharmacokinetics in human and animal models.

\section{Pharmacokinetics and Bioavailability of TDF in Patients}

TDF is formulated into a single tablet for oral administration with a standard dose of $300 \mathrm{mg}$. TDF has a higher lipophilicity than TFV. The LogP, a measure of partition

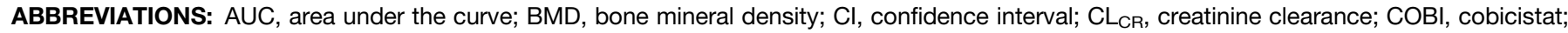
EFV, efavirenz; EVG, elvitagrir; FDA, Food and Drug Administration; FTC, emtricitabine; HIV, human immunodeficiency virus; LPV, lopinavir; MRP, multidrug resistance-associated protein; PBMC, peripheral blood mononuclear cell; PgP, P-glycoprotein efflux transporter; PrEP, pre-exposure prophylaxis; RPV, rilpivirine; $\mathrm{t}_{1 / 2}$, half life; TAF, TFV alafenamide; TDF, TFV disoproxil fumarate; TDP, TFV diphosphate; TFV, tenofovir. 
A
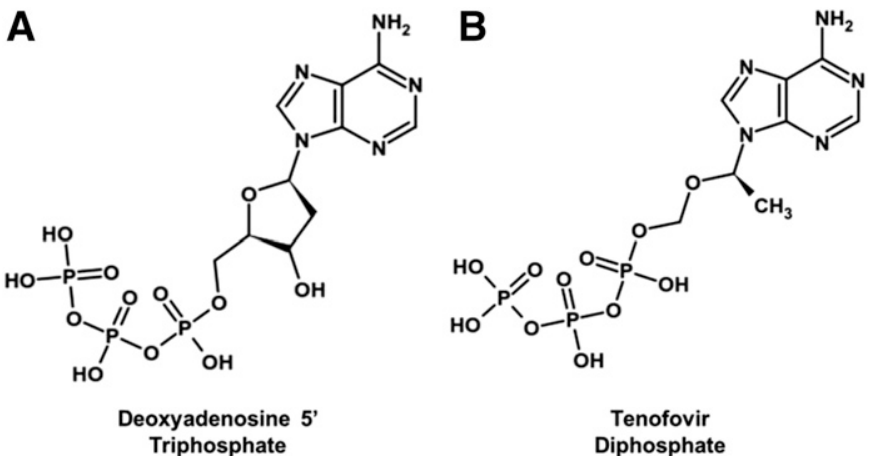

Fig. 1. Structure of deoxyadenosine $5^{\prime}$ triphosphate (A) and tenofovir diphosphate (B).

coefficient between octanol and water, is 2.1 for TDF compared with -1.6 for TFV. The higher partition coefficient would enable increased intestinal drug absorption. As a result of higher lipophilicity, TDF has an oral bioavailability of $25 \%$ in HIV-1-infected patients (Barditch-Crovo et al., 2001). Following absorption, TDF is cleaved in the plasma by esterases (Fig. 2): first to a monoester intermediate, and then to TFV (Shaw et al., 1997; Choi et al., 2008). This hydrolysis is effective enough that TDF is not observed in systemic plasma samples.

After intestinal absorption and plasma hydrolysis, TFV is phosphorylated intracellularly by adenylate kinase to its active form, TFV diphosphate (TDP) (Fig. 3). As a nucleotide analog, TFV diphosphate competes with deoxyadenosine 5' triphosphate (Fig. 1) for incorporation into the growing DNA strand during HIV transcription and blocks the activity of reverse transcriptase, leading to elongation termination (Balzarini et al., 1993; Robbins et al., 1998).

Intravenous administration of $1 \mathrm{mg} / \mathrm{kg}$ TDF has a steady state volume of distribution of $813 \mathrm{ml} / \mathrm{kg}$, indicating that tissue distribution is extensive and exceeds total body water. $\mathrm{C}_{\max }$ of the same i.v. dose is approximately $2.7 \mu \mathrm{g} / \mathrm{ml}$, and TFV serum concentration decreases in a biphasic manner (Deeks et al., 1998). The measured area under the curve (AUC) was measured AUC of $3.024 \mu \mathrm{g} \times \mathrm{h} / \mathrm{ml}$. The oral bioavailability of TDF was calculated by comparing the AUC for a $300 \mathrm{mg}$ oral dose with the AUC for a $1 \mathrm{mg} / \mathrm{kg}$ i.v. dose; oral TDF has $25 \%$ bioavailability when compared with an i.v. dose (BarditchCrovo et al., 2001).

The half life $\left(t_{1 / 2}\right)$ for a single i.v. TDF injection was 7 hours compared with 12 hours for a single oral dose of $300 \mathrm{mg}$ TDF
(Deeks et al., 1998; Barditch-Crovo et al., 2001; Hawkins et al., 2005). The intracellular $t_{1 / 2}$ of TDF is estimated to be $12-50$ hours (Robbins et al., 1998). The pharmacologic antiviral activity of TDF and ultimately TFV is proportional to the intracellular concentration in target cells. A single oral dose of TDF to macaques provided almost eightfold higher intracellular levels of the active TFV diphosphate compared with a single s.c. injection of TFV (Durand-Gasselin et al., 2009). Additionally, oral TDF shows greater accumulation in peripheral blood mononuclear cells (PBMCs) when given as an oral prodrug rather than a s.c. injection of TFV to macaques (Durand-Gasselin et al., 2009). The bioavailability in macaques was $31 \%$, which was similar to humans (Barditch-Crovo et al., 2001). These findings suggest that TDF first enhanced bioavailability, but also provided improved delivery to the target cells. The excellent uptake into cells allows for once-daily dosing. Once-daily dosing increases compliance, which will promote the therapeutic success that is important in controlling HIV as a chronic disease.

In general, differences in TDF pharmacokinetics are not apparent when comparing oral and i.v. routes of administration. Oral TDF has equivalent pharmacokinetics to i.v. TDF. Once $\mathrm{C}_{\max }$ is reached, serum TFV concentrations decline in a biphasic manner. TFV is excreted $92 \%$ unchanged by the kidney and $4.5 \%$ unchanged in feces. Renal TFV clearance exceeds calculated creatinine clearances, indicating that TFV is actively secreted by the kidneys (Cundy et al., 1998; Barditch-Crovo et al., 2001; Durand-Gasselin et al., 2009). In vitro transport studies indicate that TFV is a substrate for the multidrug resistance-associated protein (MRP)4, an apical membrane efflux transporter (Ray et al., 2006). TFV was not a substrate for MRP2. These in vitro studies would suggest that active tubular secretion of TFV into the nephron lumen is mediated by MRP4.

\section{Pharmacokinetics and Bioavailability of TDF in Patients with Renal Insufficiency}

TDF pharmacokinetics and bioavailability differ in patients with renal insufficiency, which is an important consideration in individuals with HIV. The frequency of acute kidney injury is more common in HIV-infected individuals and can progress to end-stage renal disease. In 2005, it was estimated that in the United States, almost 3000 people had end-stage renal disease related to HIV (Wyatt et al., 2008). A decline in renal
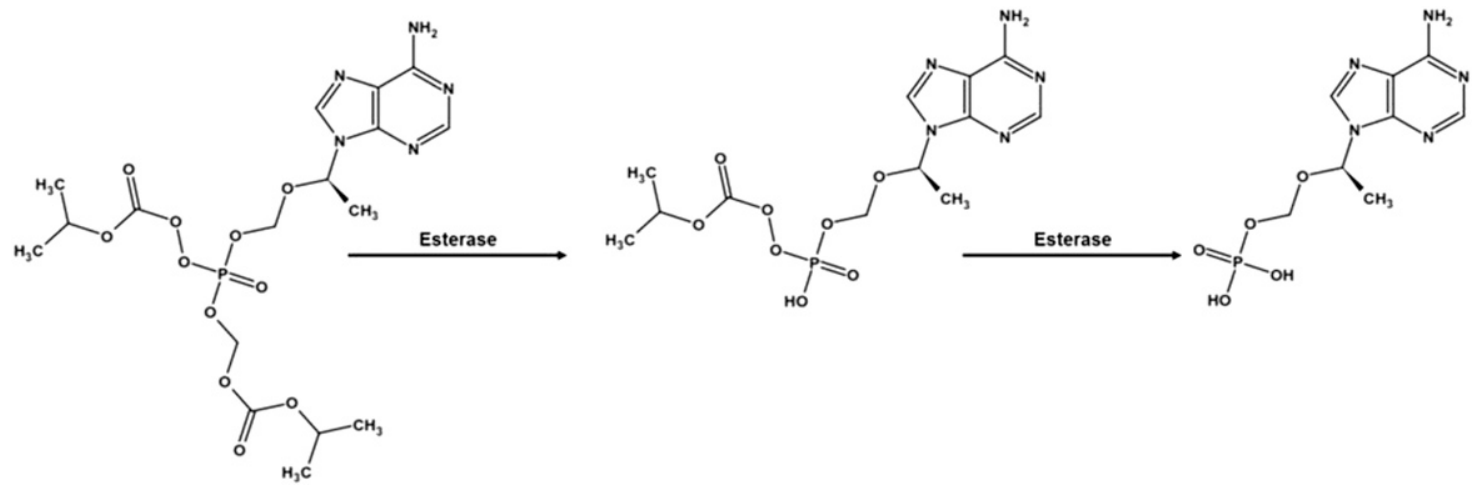

Fig. 2. Conversion of tenofovir disoproxil fumarate to tenofovir by intestinal esterases. 


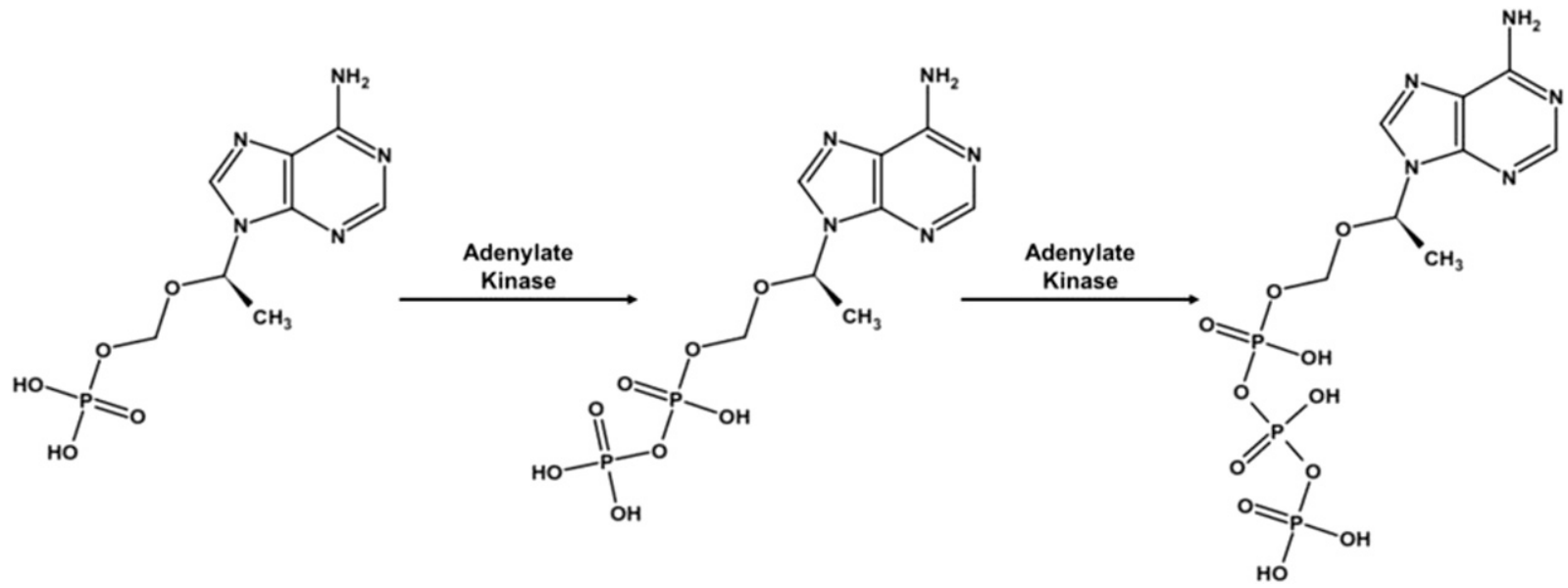

Fig. 3. Intracellular activation of tenofovir to tenofovir diphosphate by adenylate kinase.

function is a frequent occurrence in HIV disease progression (Schwartz and Klotman, 1998; Wyatt et al., 2009). HIV-associated nephropathy primarily affects the glomerulus and is characterized by proteinuria, elevated serum creatinine and blood urea nitrogen, focal segmental glomerulosclerosis, and microcystic tubular dilatation. Renal lesions lead to the collapse of the glomeruli and rapid progression to kidney failure (Laurinavicius et al., 1999; Ray, 2012).

Although HIV-associated nephropathy occurs less frequently in patients whose HIV is well controlled with antiretroviral therapy (Fabian et al., 2013), renal insufficiency should be considered when using TDF. In a study conducted in patients with varying degrees of renal insufficiency, patients with moderate and severe renal impairment [noted as creatinine clearance $\left(\mathrm{CL}_{\mathrm{CR}}\right)$ of $30-49$ and $<30 \mathrm{ml} / \mathrm{min}$, respectively] had an AUC two- to sixfold that in patients with normal renal function. The increase in AUC was most likely due to a decrease in TFV clearance that was directly proportional to the observed decreases in $\mathrm{CL}_{\mathrm{CR}}$ (Kearney et al., 2004).

Patients treated with TDF do have an increased incidence of renal impairment, and there is a positive correlation between increased TFV serum concentrations, duration of treatment with TDF, and incidence of renal toxicity (Verhelst et al., 2002; Fux et al., 2007; Ezinga et al., 2014; Quesada et al., 2015). TDF is associated with increased serum creatinine and plasma vitamin D binding, decreased free calcitriol levels and glomerular filtration rate, renal failure, and Fanconi syndrome (Hall et al., 2011; Del Palacio et al., 2012; Havens et al., 2013). Fanconi syndrome is a disorder of renal tubular function characterized by excess excretion of potassium, phosphate salts, protein, urate, and glucose. Clinical studies indicate that the mitochondria of the proximal tubules are the target of TFV-induced toxicity, as shown by enlarged and malformed mitochondria in electron microscopy cross sections (Côté et al., 2006; Woodward et al., 2009; Herlitz et al., 2010; Hall et al., 2011). Proximal tubular mitochondrial toxicity has also been described in mice and rats treated with TFV, as shown by disruptions in mitochondrial cristae and a reduction in mitochondrial DNA levels (Kohler et al., 2009; Lebrecht et al., 2009).

Changes in TDF administration are recommended for patients with decreased renal function to reduce plasma concentrations and to prevent worsening of renal damage. In patients with moderate impairment $\left(\mathrm{CL}_{\mathrm{CR}} 30-49 \mathrm{ml} / \mathrm{min}\right), 300 \mathrm{mg}$ dose of TDF should be reduced in frequency to once every 48 hours instead of once daily. In patients with severe impairment $\left(\mathrm{CL}_{\mathrm{CR}}\right.$ $10-29 \mathrm{ml} / \mathrm{min}$ ) or those who are on hemodialysis, the $300 \mathrm{mg}$ dose should be administered every 72-96 hours or once every 7 days, respectively (Gilead Sciences, 2001).

\section{Pharmacokinetics and Bioavailability of TDF in Fixed-Dose Combination Tablets}

To simplify HIV treatment regimens and increase compliance, TDF is commonly paired with other antiretrovirals in single-dose combination tablet. The drugs currently combined with TDF in fixed-dose combinations are as follows: emtricitabine (FTC), efavirenz (EFV), rilpivirine (RPV), the integrase strand transfers inhibitor elvitegravir (EVG), and the CYP 3A4 inhibitor cobicistat (COBI). The most common formulations are as follows: TDF/FTC, TDF/FTC/EFV, TDF/FTC/ RPV, and TDF/FTC/EVG/COBI. Each formulation includes TDF as a standard $300 \mathrm{mg}$ dose. Bioequivalence is evaluated in combination tablet formulations by maintenance of pharmacokinetic parameters $\mathrm{C}_{\max }, \mathrm{AUC}$, and $\mathrm{t}_{1 / 2}$ within a confidence interval (CI) of $80 \%-125 \%$ of the reference formulation.

The first fixed-dose combination approved by the FDA for treatment of HIV-contained TDF/FTC/EFV. FTC, EFV, and TDF all have $t_{1 / 2}$ that are suitable for once per day dosing (FTC, 39 hours; EFV, 23 hours; TDF, 15-60 hours) (Barditch-Crovo et al., 2001; DiCenzo et al., 2003; Hawkins et al., 2005; Saag, 2006). When studied as a fixed-dose combination tablet, all pharmacokinetic parameters had geometric mean ratios close to $100 \%$ and $90 \%$ CI within the bioequivalence bounds of individual formulations, indicating that TDF, EFV, and FTC can be combined into a once-daily combination tablet (Mathias et al., 2007). The combination of TDF/FTC/EFV is FDA approved as a complete regimen for HIV treatment and can also be used in combination with other HIV medications (Gilead Sciences, 2006).

TDF/FTC/RPV combination provides two nucleos(t)ide reversetranscriptase inhibitors (TDF/FTC) with a non-nucleoside reverse-transcriptase inhibitor, $\mathrm{RPV}$, to treat $\mathrm{HIV}$. Initial studies showed that addition of $25 \mathrm{mg}$ RPV to a TDF/FTC treatment regimen showed equivalence in HIV suppression when compared with TDF/FTC + EFV regimens and had less adverse effects than EFV (Cohen et al., 2011; Molina et al., 2011). 
RPV has a $t_{1 / 2}$ of approximately 50 hours, making it a suitable candidate for inclusion in a once-daily combination tablet (Cohen et al., 2013). In a bioequivalence study, all pharmacokinetic parameters of a TDF/FTC/RPV single-dose tablet demonstrated a $90 \%$ CI within the bioequivalence bounds of individual formulations, indicating that TDF, FTC, and RPV can be combined into a once-daily combination tablet. Although both TDF and FTC are approved to be taken with or without a meal, RPV bioavailability is reduced $40 \%$ in a fasted state alone and in a combination tablet. Therefore, TDF/FTC/ RPV should be taken with food (Mathias et al., 2012).

TDF/FTC combination tablets also demonstrate bioequivalence for all tested pharmacokinetic parameters when compared with individual therapy (Blum et al., 2007). TDF/FTC is FDA approved to treat HIV-1 in conjunction with other therapies, but is not considered a complete regimen. TDF/ FTC is also FDA approved for use in pre-exposure prophylaxis (PrEP) therapy to prevent the transmission of HIV-1 between sexual partners (Grant et al., 2010; Anderson et al., 2012; Baeten et al., 2012). The use of TFV-containing regimens for PrEP is discussed in further detail below.

Recently, COBI has been included in highly active antiretroviral therapy to treat HIV. Although it has no antiviral activity on its own, COBI is a pharmacoenhancer for drugs that are metabolized by cytochrome P450 3A enzymes (CYP3A). COBI is a potent CYP3A inhibitor, and is commonly used with protease and integrase inhibitors such as EVG in the treatment of HIV. In a fixed-dose combination study, administration of COBI/TDF/EVG combination tablets showed bioequivalence; however, TDF $\mathrm{C}_{\max }$ was increased $30 \%$, but AUC was largely unaffected (German et al., 2010). COBI may alter the $t_{1 / 2}$ of other drugs taken concurrently that are biotransformed by CYP3A as inhibition by COBI may slow biotransformation by CYP3A. COBI is a substrate for CYP3A, and treatment with agents that induce or inhibit CYP3A has the potential to alter the effects of COBI (Sherman et al., 2015).

This increase in $\mathrm{C}_{\max }$ may be due to COBI's transient inhibition of P-glycoprotein efflux transporter (Pgp); TFV is a recognized substrate of the PgP transporter (German et al., 2010; Lepist et al., 2012). It is worth noting that COBI inhibition of P-glycoprotein is weak, much like other protease inhibitors such as ritonavir (RTV); COBI, RTV, and other protease inhibitors do not inhibit efflux transporters at pharmacologically relevant concentrations in systemic circulation (Washington et al., 1998; Polli et al., 1999; van der Sandt et al., 2001; Ray et al., 2006; Cihlar et al., 2007) but may reach concentrations high enough to inhibit efflux transporters in the gut (Ray et al., 2006; Tong et al., 2007).

\section{Effect of Food Intake on TDF Bioavailability}

Taking TDF with food has shown to improve bioavailability. However, it does not appear that the type of meal matters, as no changes in pharmacokinetic parameters are seen with administration of a standard meal, high-fat meal, or protein-rich meal. In a study of healthy Japanese males, participants ingested a standard meal (11.4 g protein, $9.6 \mathrm{~g}$ fat, and $72.2 \mathrm{~g}$ carbohydrates) or a protein-rich drink ( $8.8 \mathrm{~g}$ protein, $8.8 \mathrm{~g}$ fat, and $34.3 \mathrm{~g}$ carbohydrates) prior to administration of a $300 \mathrm{mg}$ dose of TDF. There was a $28 \%$ decrease in both AUC and $\mathrm{C}_{\max }$ when TDF was administered in a fasted state compared with administration following a standard meal or a protein-rich drink.
Although $\mathrm{C}_{\max }$ was slightly lower in the protein-drink group (554 ng/ml versus $613 \mathrm{ng} / \mathrm{ml}$ ), AUC and $\mathrm{t}_{1 / 2}$ were not different between meals, indicating that a standard meal and a proteinrich drink produce bioequivalent increases in TDF bioavailability over fasted administration (Shiomi et al., 2014).

Bioavailability of TDF was increased in one study using a very high-fat meal in uninfected males. Effects of a very highfat meal were evaluated during phase I testing of TDF in healthy males. Participants ingested a high-fat meal (50\% fat, $1000 \mathrm{kcal}) 30$ minutes prior to administration of TDF. TDF bioavailability in the fed group was increased $40 \%$ over the fasted group, and $\mathrm{C}_{\max }$ was increased $14 \%$. $\mathrm{T}_{\max }$ also increased from 0.5 to 1 hour in a fasted state to 1.3-3 hours in a fed state, consistent with a slowing of gastric emptying following a meal (Barditch-Crovo et al., 2001; Kearney et al., 2004). This same group noted that a high-fat meal was not indicative of normal diet, and studied the effects of a light meal on TDF bioavailability and found no significant effect. According to its prescribing information, TDF can be administered with or without a meal (Gilead Sciences, 2001). It should be noted that certain TDF fixed-dose combination formulations such as TDF/FTC/RPV and TDF/FTC/EVG/COBI should be taken with food due to significant decreases in RPV (40\%) and EVG (50\%) bioavailability in a fasted state (German et al., 2010; Mathias et al., 2012; Shiomi et al., 2014).

Although TDF is intended to be cleaved by plasma esterases, it is susceptible to cleavage by intestinal carboxylesterases when administered by the oral route. It is hypothesized that this intestinal hydrolysis and efflux via Pgp are what limits TDF bioavailability in humans (Shaw et al., 1997; Yuan et al., 2001; van Gelder et al., 2002). Ester-rich fruit juices such as grapefruit, orange, cranberry, and concord grape have been shown to increase oral absorption of drugs such as lopinavir (LPV) and saquinavir through inhibition of Pgp, MRP2, and various cytochrome P450s (CYPs) (Bailey et al., 1998; Honda et al., 2004; Ravi et al., 2015). As TDF is a substrate of Pgp, studies were done to determine whether ester-rich fruit juices increase its bioavailability and intestinal absorption. Strawberry juice extract increased TDF intestinal absorption in Caco2 cell lines to $67 \%$, whereas grapefruit and cranberry juice extracts increased TDF bioavailability by $97 \%$ and $24 \%$ in an in vivo rat study (Van Gelder et al., 1999; Shailender et al., 2017). Additional investigation needs to be done to determine whether this effect is also seen in humans.

\section{Age-Related Differences in TFV Bioavailability and Pharmacokinetics}

TDF is FDA approved for use in the United States in children age 2 and older. As HIV is a chronic disease, it is important to determine the developmentally associated changes in pharmacokinetic parameters of antiretroviral therapy. Studies have been conducted to determine the pharmacokinetic profile of TDF administration in neonates, children/adolescents, and adults. TDF pharmacokinetics vary in children comparatively to adults, and these variables need to be considered when determining dosing. Initial pharmacokinetic studies were run following TDF's approval for use in adults. Hazra et al. (2004) determined the adult-equivalent dose in children to be $\sim 175 \mathrm{mg} / \mathrm{m}^{2}$ based on calculations from initial pharmacokinetic studies in adults. In a cohort of 
children ranging from 4 to 18 years of age given $175 \mathrm{mg}$ TDF for 4 weeks, AUC and $\mathrm{C}_{\max }$ were reported to be $34 \%$ and $27 \%$ lower than the equivalent dose in adults. The decrease in AUC may be explained by the observed 1.5 times faster clearance in children (Barditch-Crovo et al., 2001; Hazra et al., 2004).

Studies in which HIV-positive children were administered a full adult dose of TDF once daily showed similar pharmacokinetic changes observed in the initial pharmacokinetic study. Children and adolescents (defined as $<25$ years old) have lower plasma concentrations of TFV compared with adult patients, and clearance in children was $36 \%$ faster, which may contribute to the lower plasma concentration. The increase in clearance may be due to a larger relative kidney relative to body size as well as increased renal function (King et al., 2011; Baheti et al., 2013). Additionally, Baheti et al. (2013) reported that children have almost 50\% higher intracellular concentrations of TDP following oral administration compared with adults. This phenomenon may be due to a lower effective concentration, $\mathrm{EC}_{50}$, seen in children rather than adults for TFV (100 ng/ml versus $192 \mathrm{ng} / \mathrm{ml}$, respectively).

Although no significant adverse effects were initially observed in studies using an adult dose, studies have also been conducted to determine effective weight-band TDF dosing in children due to concerns of bone density loss at different stages of bone dynamics. Longitudinal assessment of available data determined an overall incidence of bone mineral density (BMD) loss in children taking TDF at $24 \%-32 \%$; this loss occurs within 6-12 months of initiation of treatment and then stabilizes (O'Brien et al., 2001; Jacobson et al., 2010; Puthanakit et al., 2012; Schtscherbyna et al., 2012; Aurpibul et al., 2015).

A study conducted in children age 9-18 years also saw increased TFV clearance relative to adults, although clearance increased with body weight. Because of the differences in clearance, this model recommends prescribing TDF to children based on weight to achieve adult AUC: $150 \mathrm{mg}$ at 20-30 kg body weight, $225 \mathrm{mg}$ at $30-40 \mathrm{~kg}$ body weight, and the full adult dose of $300 \mathrm{mg}$ at over $40 \mathrm{~kg}$ body weight (Bouazza et al., 2011); no mention of adverse effects was made in this study. Another study conducted based on weight-band dosing in children 3-17 years determined similar dosing parameters: $150 \mathrm{mg}$ at $15-21 \mathrm{~kg}$ body weight, $225 \mathrm{mg}$ at $22-33 \mathrm{~kg}$ body weight, and a full adult dose of $300 \mathrm{mg}$ at $>33 \mathrm{~kg}$ body weight. In this 96 -week study, $28 \%$ of patients experienced a decrease in BMD by 24 weeks, at which point BMD remained constant (Aurpibul et al., 2015).

TDF is most commonly administered in children as part of a treatment regimen also containing LPV and RTV, unlike adults who are commonly prescribed single-dose combination tablets (see previous section). It is relevant to note that LPV increases TDF AUC by $34 \%$ and serum concentration by $30 \%$ in adults (Barditch-Crovo et al., 2001; Kearney et al., 2004). This phenomenon is also seen in children, and is attributed to the observed $25 \%$ decrease in TDF clearance when coadministered with LPV (Bouazza et al., 2011; Aurpibul et al., 2015). It is recommended that TDF dosing be adjusted in children when coadministered with LPV: $150 \mathrm{mg}$ at $20-40 \mathrm{~kg}$ body weight, $225 \mathrm{mg}$ at $40-50 \mathrm{~kg}$ body weight, and $300 \mathrm{mg}$ at $>55 \mathrm{~kg}$ body weight (Bouazza et al., 2011).

TDF is approved to treat HIV in children $>2$ years of age in combination with other medications. It is recommended that dosage be adjusted according to body weight in children $<12$ years of age (Gilead Sciences, 2001). Additional studies need to be conducted on the observed interaction of TDF with LPV, as well as monitoring the incidence of bone density loss in children. Additional research is needed to evaluate the effect of age on the renal tubular transporters and potential impact on TFV clearance. TFV is a substrate for the efflux transporter MRP4. A study in rats reported that MRP4 expression developed slower than the basolateral membrane transporters, organic anion transporters 1 and 3 (Nomura et al., 2012). The developmental expression of MRP4 and other transporters is an area of limited information and may explain some of the differences related to TFV clearance with age.

\section{TFV as a Prophylactic Agent: Sex-Related Differences in Pharmacokinetics}

TDF is commonly used for antiretroviral PrEP in HIVuninfected patients who engage in high-risk sexual encounters. Studies evaluating oral TDF/FTC PrEP efficacy show modest protection (76\%) when taken twice per week and $75 \%$ 99\% infection protection when taken every day. Studies using oral TDF $300 \mathrm{mg}$ tablets as PrEP show a $67 \%$ reduction in HIV incidence, but high adherence was necessary (Anderson et al., 2012; Baeten et al., 2012). It should be noted that, although TFV pharmacokinetics are similar, there are documented differences in TDP intracellular concentrations in HIVinfected and uninfected patients; TDP concentrations are higher in HIV-infected patients (120 fmol/million cells) than in healthy patients (42 fmol/million cells) (Anderson et al., 2012; Baheti et al., 2013). Currently, TDF/FTC is the only FDA-approved PrEP regimen; it must be taken daily in conjunction with safer sex practices and HIV-status monitoring every 3 months. HIV-status monitoring is critical as HIV-1 resistance has been documented in cases of undetected infection when using TDF/FTC (Gilead Sciences, 2004).

To evaluate PrEP options for women, studies have been conducted to determine the efficacy of a topical 1\% TDF gel formulation in the prevention of HIV infection. The original CAPRISA clinical trial showed modest protection, with an incidence of reduction ranging from $39 \%$ to $54 \%$ depending on adherence (Abdool Karim et al., 2010). TDP intracellular concentrations were not measured. A study of PrEP regimens of TDF, TDF/FTC, or 1\% TDF vaginal gel in African women determined that there was no effect in the prevention of HIV transmission (Marrazzo et al., 2015); again, TDP concentration was not measured. Currently, $1 \%$ gel TDF formulation is not approved for PrEP, as efficacy has to date been shown to be moderate at best.

Recently, clinical studies were done to determine the differences in TFV-diphosphate distribution in healthy women using the TDF $1 \%$ gel, TDF $300 \mathrm{mg}$ oral tablet, or both. TDP vaginal concentration was 130 -fold higher in patients using the topical gel than oral dosing, but systemic TDP concentrations were 56-fold lower. Combination regimens of oral and topical TDF resulted in vaginal tissue concentrations threefold higher than in groups that used the oral formulation alone (Hendrix et al., 2013; Burns et al., 2015). Efficacy as a PrEP regimen was not directly measured in this study.

The extremely high vaginal concentrations of TDP may be due in part to hormonal regulation. Estradiol increases the amount of TDP present in isolated epithelial cells from the female reproductive tract, progesterone has no effect, and 
estradiol-progesterone combination treatment negates the stimulatory effect of estradiol. In CD4 cells isolated from the female reproductive tract, progesterone alone and in combination with estradiol greatly reduced TDP concentration (Shen et al., 2014). These results suggest that hormonal regulation of TFV phosphorylation is dependent on cell type. It has been hypothesized that women experience a 7- to 10-day window of increased susceptibility to HIV infection due to immune suppression by sex hormones following ovulation (Wira and Fahey, 2008). The changes in TDF uptake and activation in the female reproductive tract may be due to the hormonal responses seen in previous studies.

It is worth noting that, whereas TDP concentrations vary in the female reproductive tract, administration of TDF with oral contraceptive pills did not change either TFV or oral contraceptive pill systemic levels (Kearney and Mathias, 2009). The observed responsiveness to sex hormones may be limited to tissues within the reproductive tract; additional study needs to be done in this area to fully determine the relationship between TDF pharmacokinetics and sex hormones.

TDF has also been examined in late pregnancy and labor to prevent vertical transmission of HIV. One study gave $300 \mathrm{mg}$ TDF at the onset of labor, and to neonates within 12 hours of birth to infected mothers; a $13 \mathrm{mg} / \mathrm{kg}$ neonate dose produced intracellular TDP concentrations similar to adult levels (Hirt et al., 2011). However, plasma concentration remains low, as seen in children taking TDF, and there is a delay in the presence of TDP in neonatal PBMCs. There was no quantifiable TDP in fetal PBMCs. The delay in TFV phosphorylation could be due to differences in enzyme expression and activity in neonates versus children. Another study showed similar results: HIV-infected mothers were given a $600 \mathrm{mg}$ dose of TDF, and neonates were given a $6 \mathrm{mg} / \mathrm{kg}$ daily dose, resulting in plasma concentrations similar to those seen in adults. Infant clearance was also equivalent to that seen in older children (Mirochnick et al., 2014).

It is important to note that TDF pharmacokinetics are slightly altered during pregnancy. During the third trimester, TDF AUC is $20 \%$ lower compared with postpartum levels. This transient difference may be directly attributable to increased weight and faster clearance during the last trimester of pregnancy (Best et al., 2015). Additional research needs to be done to determine changes in pharmacokinetic parameters during pregnancy, and how these changes affect vertical HIV transmission to children.

\section{Alternative TFV Prodrug Formulations}

Recently, TFV alafenamide (TAF) has undergone phase I-III testing and was approved to treat chronic hepatitis B in 2016. TAF has greater plasma stability, more effective cellular loading than TDF, and maintains a similar oral bioavailability at $17 \%$. TAF has an $\mathrm{EC}_{50}$ of $0.005 \mu \mathrm{M}$ rather than $5 \mu \mathrm{M}$ seen with TDF, leading to significantly less plasma exposure, and by association lower systemic side effects (Lee et al., 2005; Sax et al., 2015; Buti et al., 2016). TAF underwent phase I-II testing in HIV patients, but did not make it to phase III due to the risk of HIV-1 resistance.

TAF has been approved to replace TDF in fixed-dose combination tablets to treat HIV following phase III trials. The combination product of TAF/FTC/COBI/EVG demonstrated $90 \%$ virologic success in both treatment-naive and treatment-experienced patients with lower incidence of adverse renal and bone effects when compared with TDF/ FTC/COBI/EVG (Gilead Sciences, 2015b; Sax et al., 2015; Mills et al., 2016; Pozniak et al., 2016; Wohl et al., 2016). The combined preparation of TAF/FTC demonstrated $93 \%$ virologic success when compared with the combination of TDF/FTC, with no documented renal tubulopathy in either test group. It should be noted that whereas TDF/FTC is recommended as a PrEP regimen, TDF/FTC is not approved for PrEP regimen by the FDA as of May 2017 (Gilead Sciences, 2015a; Sax et al., 2015; Gallant et al., 2016; Mills et al., 2016). Although TDF is currently FDA approved for HIV-1 treatment in patients 2 years of age and older, TAF fixed-dose combinations are only indicated for patients greater than 12 years of age.

The use of liposomes and niosomes has been investigated to improve the bioavailability of TDF. When encapsulated in a liposome made of phospholipids and 7.5\% cholesterol, TDF had an increased permeability rate across Caco-2 cells (3.71E$07 \mathrm{~cm} / \mathrm{s}$ ) compared with TDF alone $(4.18 \mathrm{E}-07 \mathrm{~cm} / \mathrm{s}$ ) (Spinks et al., 2017). When encapsulated in a niosome created with sorbitan monoesterate in a 1:1 ratio, $>99 \%$ of the TDF dose was released in vitro within 24 hours. In a subsequent in vivo study in rats, TDF AUC was increased twofold when encapsulated in a niosome compared with $\mathrm{TDF}$ alone; $\mathrm{C}_{\max }, \mathrm{T}_{1 / 2}$, and $\mathrm{T}_{\max }$ were also increased, possibly due to increased GI absorption and the release-retarding effects of niosomes (Azmin et al., 1985; Kamboj et al., 2014). No studies have yet been conducted to determine whether liposomes or niosomes are more efficient in improving TDF bioavailability or if encapsulation is effective in humans for the treatment of HIV using TDF.

\section{Conclusions}

TDF is the prodrug for TFV, which is a nucleotide analog reverse-transcriptase inhibitor that is very effective in the treatment of HIV and chronic hepatitis B. TDF has a favorable pharmacokinetic profile, allowing for once per day dosing, and its pharmacokinetics are largely unchanged when given in fixed-dose combination tablets. TDF has been shown to be effective as a prophylactic agent to prevent HIV-1 transmission, leading to site-specific formulations; this area of research remains highly active. TDF does have limited oral bioavailability, and research is active to determine whether bioavailability can be increased. More importantly, TDF improves intracellular concentration in PBMCs. Overall, TDF remains one of the first-line agents in the treatment of $\mathrm{HIV}$ and hepatitis B virus, providing once-daily dosing, which improves patient compliance.

\section{Authorship Contributions}

Wrote or contributed to the writing of the manuscript: Murphy, Valentovic.

\section{References}

Abdool Karim Q, Abdool Karim SS, Frohlich JA, Grobler AC, Baxter C, Mansoor LE, Kharsany AB, Sibeko S, Mlisana KP, Omar Z, et al.; CAPRISA 004 Trial Group (2010) Effectiveness and safety of tenofovir gel, an antiretroviral microbicide, for the prevention of HIV infection in women. Science 329:1168-1174.

Anderson PL, Glidden DV, Liu A, Buchbinder S, Lama JR, Guanira JV, McMahan V, Bushman LR, Casapía M, Montoya-Herrera O, et al.; iPrEx Study Team (2012) Emtricitabine-tenofovir concentrations and pre-exposure prophylaxis efficacy in men who have sex with men. Sci Transl Med 4:151ra125.

Aurpibul L, Cressey TR, Sricharoenchai S, Wittawatmongkol O, Sirisanthana V, Phongsamart W, Sudjaritruk T, and Chokephaibulkit K (2015) Efficacy, safety and pharmacokinetics of tenofovir disoproxil fumarate in virologic-suppressed 
HIV-infected children using weight-band dosing. Pediatr Infect Dis $J$ 34: 392-397.

Azmin MN, Florence AT, Handjani-Vila RM, Stuart JF, Vanlerberghe G, and Whittaker JS (1985) The effect of non-ionic surfactant vesicle (niosome) entrapment on the absorption and distribution of methotrexate in mice. J Pharm Pharmacol 37:237-242.

Baeten JM, Donnell D, Ndase P, Mugo NR, Campbell JD, Wangisi J, Tappero JW, Bukusi EA, Cohen CR, Katabira E, et al.; Partners PrEP Study Team (2012) Antiretroviral prophylaxis for HIV prevention in heterosexual men and women. $N$ Engl J Med 367:399-410.

Baheti G, King JR, Acosta EP, and Fletcher CV (2013) Age-related differences in plasma and intracellular tenofovir concentrations in HIV-1-infected children, adolescents and adults. AIDS 27:221-225.

Bailey DG, Malcolm J, Arnold O, and Spence JD (1998) Grapefruit juice-drug interactions. $\mathrm{Br} J$ Clin Pharmacol 46:101-110.

Balzarini J, Holy A, Jindrich J, Naesens L, Snoeck R, Schols D, and De Clercq E (1993) Differential antiherpesvirus and antiretrovirus effects of the (S) and (R) enantiomers of acyclic nucleoside phosphonates: potent and selective in vitro and in vivo antiretrovirus activities of (R)-9-(2-phosphonomethoxypropyl)-2,6-diaminopurine. Antimicrob Agents Chemother 37:332-338.

Barditch-Crovo P, Deeks SG, Collier A, Safrin S, Coakley DF, Miller M, Kearney BP, Coleman RL, Lamy PD, Kahn JO, et al. (2001) Phase i/ii trial of the pharmacokinetics, safety, and antiretroviral activity of tenofovir disoproxil fumarate in human immunodeficiency virus-infected adults. Antimicrob Agents Chemother 45:2733-2739.

Best BM, Burchett S, Li H, Stek A, Hu C, Wang J, Hawkins E, Byroads M, Watts DH, Smith E, et al.; International Maternal Pediatric and Adolescent AIDS Clinical Trials (IMPAACT) P1026s Team (2015) Pharmacokinetics of tenofovir during pregnancy and postpartum. HIV Med 16:502-511.

Blum MR, Chittick GE, Begley JA, and Zong J (2007) Steady-state pharmacokinetics of emtricitabine and tenofovir disoproxil fumarate administered alone and in combination in healthy volunteers. J Clin Pharmacol 47:751-759.

Bouazza N, Urien S, Hirt D, Frange P, Rey E, Benaboud S, Foissac F, Blanche S, and Tréluyer JM (2011) Population pharmacokinetics of tenofovir in HIV1-infected pediatric patients. J Acquir Immune Defic Syndr 58:283-288.

Burns RN, Hendrix CW, and Chaturvedula A (2015) Population pharmacokinetics of tenofovir and tenofovir-diphosphate in healthy women. J Clin Pharmacol 55 $629-638$.

Buti M, Gane E, Seto WK, Chan HL, Chuang WL, Stepanova T, Hui AJ, Lim YS, Mehta R, Janssen HL, et al.; GS-US-320-0108 Investigators (2016) Tenofovir alafenamide versus tenofovir disoproxil fumarate for the treatment of patients with HBeAg-negative chronic hepatitis B virus infection: a randomised, double-blind, phase 3, non-inferiority trial. Lancet Gastroenterol Hepatol 1:196-206.

Choi SU, Bui T, and Ho RJ (2008) pH-dependent interactions of indinavir and lipids in nanoparticles and their ability to entrap a solute. J Pharm Sci 97:931-943.

Cihlar T, Ray AS, Laflamme G, Vela JE, Tong L, Fuller MD, Roy A, and Rhodes GR (2007) Molecular assessment of the potential for renal drug interactions between tenofovir and HIV protease inhibitors. Antivir Ther 12:267-272.

Cohen CJ, Andrade-Villanueva J, Clotet B, Fourie J, Johnson MA, Ruxrungtham K, Wu H, Zorrilla C, Crauwels H, Rimsky LT, et al.; THRIVE Study Group (2011) Rilpivirine versus efavirenz with two background nucleoside or nucleotide reverse transcriptase inhibitors in treatment-naive adults infected with HIV-1 (THRIVE): a phase 3, randomised, non-inferiority trial. Lancet 378:229-237.

Cohen CJ, Molina JM, Cassetti I, Chetchotisakd P, Lazzarin A, Orkin C, Rhame F, Stellbrink HJ, Li T, Crauwels H, et al.; ECHO, THRIVE Study Groups (2013) Week 96 efficacy and safety of rilpivirine in treatment-naive, HIV-1 patients in two phase III randomized trials. AIDS 27:939-950.

Côté HC, Magil AB, Harris M, Scarth BJ, Gadawski I, Wang N, Yu E, Yip B, Zalunardo N, Werb R, et al. (2006) Exploring mitochondrial nephrotoxicity as a potential mechanism of kidney dysfunction among HIV-infected patients on highly active antiretroviral therapy. Antivir Ther 11:79-86.

Cundy KC, Sueoka C, Lynch GR, Griffin L, Lee WA, and Shaw JP (1998) Pharmacokinetics and bioavailability of the anti-human immunodeficiency virus nucleotide analog 9-[(R)-2-(phosphonomethoxy)propyl]adenine (PMPA) in dogs. Antimicrob Agents Chemother 42:687-690.

Deeks SG, Barditch-Crovo P, Lietman PS, Hwang F, Cundy KC, Rooney JF, Hellmann NS, Safrin S, and Kahn JO (1998) Safety, pharmacokinetics, and antiretroviral activity of intravenous 9-[2-(R)-(phosphonomethoxy)propyl]adenine, a novel anti-human immunodeficiency virus (HIV) therapy, in HIV-infected adults. Antimicrob Agents Chemother 42:2380-2384.

Del Palacio M, Romero S, and Casado JL (2012) Proximal tubular renal dysfunction or damage in HIV-infected patients. AIDS Rev 14:179-187.

DiCenzo R, Forrest A, Squires KE, Hammer SM, Fischl MA, Wu H, Cha R, and Morse GD; Adult AIDS Clinical Trials Group Protocol 368/886 Study Team (2003) Indinavir, efavirenz, and abacavir pharmacokinetics in human immunodeficiency virus-infected subjects. Antimicrob Agents Chemother 47:1929-1935.

Durand-Gasselin L, Van Rompay KK, Vela JE, Henne IN, Lee WA, Rhodes GR, and Ray AS (2009) Nucleotide analogue prodrug tenofovir disoproxil enhances lymphoid cell loading following oral administration in monkeys. Mol Pharm 6: $1145-1151$.

Ezinga M, Wetzels JF, Bosch ME, van der Ven AJ, and Burger DM (2014) Long-term treatment with tenofovir: prevalence of kidney tubular dysfunction and its association with tenofovir plasma concentration. Antivir Ther 19:765-771.

Fabian J, Naicker S, Goetsch S, and Venter WD (2013) The clinical and histological response of HIV-associated kidney disease to antiretroviral therapy in South Africans. Nephrol Dial Transplant 28:1543-1554.

Fux CA, Simcock M, Wolbers M, Bucher HC, Hirschel B, Opravil M, Vernazza P, Cavassini M, Bernasconi E, Elzi L, et al.; Swiss HIV Cohort Study (2007) Tenofovir use is associated with a reduction in calculated glomerular filtration rates in the Swiss HIV cohort study. Antivir Ther 12:1165-1173.
Gallant JE, Daar ES, Raffi F, Brinson C, Ruane P, DeJesus E, Johnson M, Clumeck N, Osiyemi O, Ward D, et al. (2016) Efficacy and safety of tenofovir alafenamide versus tenofovir disoproxil fumarate given as fixed-dose combinations containing emtricitabine as backbones for treatment of HIV-1 infection in virologically suppressed adults: a randomised, double-blind, active-controlled phase 3 trial. Lancet HIV 3:e158-e165.

German P, Warren D, West S, Hui J, and Kearney BP (2010) Pharmacokinetics and bioavailability of an integrase and novel pharmacoenhancer-containing singletablet fixed-dose combination regimen for the treatment of HIV. J Acquir Immune Defic Syndr 55:323-329.

Gilead Sciences (2001) Full Prescribing Information, Viread, Gilead Sciences, Foster City, CA.

Gilead Sciences (2004) Full Prescribing Information, Truvada, Gilead Sciences, Foster City, CA.

Gilead Sciences (2006) Full Prescribing Information, Atripla, Gilead Sciences, Foster City, CA.

Gilead Sciences (2015a) Full Prescribing Information, Descovy, Gilead Sciences, Foster City, CA.

Gilead Sciences (2015b) Full Prescribing Information, Genvoya, Gilead Sciences, Foster City, CA.

Grant RM, Lama JR, Anderson PL, McMahan V, Liu AY, Vargas L, Goicochea P, Casapía M, Guanira-Carranza JV, Ramirez-Cardich ME, et al.; iPrEx Study Team (2010) Preexposure chemoprophylaxis for HIV prevention in men who have sex with men. N Engl J Med 363:2587-2599.

Hall AM, Hendry BM, Nitsch D, and Connolly JO (2011) Tenofovir-associated kidney toxicity in HIV-infected patients: a review of the evidence. Am J Kidney Dis 57: 773-780.

Havens PL, Kiser JJ, Stephensen CB, Hazra R, Flynn PM, Wilson CM, Rutledge B, Bethel J, Pan CG, Woodhouse LR, et al.; Adolescent Medicine Trials Network for HIV/AIDS Interventions (ATN) 063 Study Team (2013) Association of higher plasma vitamin D binding protein and lower free calcitriol levels with tenofovir disoproxil fumarate use and plasma and intracellular tenofovir pharmacokinetics: cause of a functional vitamin D deficiency? Antimicrob Agents Chemother 57: 5619-5628.

Hawkins T, Veikley W, St Claire RL, III, Guyer B, Clark N, and Kearney BP (2005) Intracellular pharmacokinetics of tenofovir diphosphate, carbovir triphosphate, and lamivudine triphosphate in patients receiving triple-nucleoside regimens. $J$ Acquir Immune Defic Syndr 39:406-411.

Hazra R, Balis FM, Tullio AN, DeCarlo E, Worrell CJ, Steinberg SM, Flaherty JF, Yale K, Poblenz M, Kearney BP, et al. (2004) Single-dose and steady-state pharmacokinetics of tenofovir disoproxil fumarate in human immunodeficiency virusinfected children. Antimicrob Agents Chemother 48:124-129.

Hendrix CW, Chen BA, Guddera V, Hoesley C, Justman J, Nakabiito C, Salata R, Soto-Torres L, Patterson K, Minnis AM, et al. (2013) MTN-001: randomized pharmacokinetic cross-over study comparing tenofovir vaginal gel and oral tablets in vaginal tissue and other compartments. PLoS One 8:e55013.

Herlitz LC, Mohan S, Stokes MB, Radhakrishnan J, D’Agati VD, and Markowitz GS (2010) Tenofovir nephrotoxicity: acute tubular necrosis with distinctive clinical, pathological, and mitochondrial abnormalities. Kidney Int 78:1171-1177.

Hirt D, Ekouévi DK, Pruvost A, Urien S, Arrivé E, Blanche S, Avit D, Amani-Bosse C, Nyati M, Legote S, et al. (2011) Plasma and intracellular tenofovir pharmacokinetics in the neonate (ANRS 12109 trial, step 2). Antimicrob Agents Chemother $\mathbf{5 5}$ : 2961-2967.

Honda Y, Ushigome F, Koyabu N, Morimoto S, Shoyama Y, Uchiumi T, Kuwano M, Ohtani H, and Sawada Y (2004) Effects of grapefruit juice and orange juice components on P-glycoprotein- and MRP2-mediated drug efflux. $\mathrm{Br} J$ Pharmacol 143: $856-864$.

Jacobson DL, Lindsey JC, Gordon CM, Moye J, Hardin DS, Mulligan K, and Aldrovandi GM; Pediatric AIDS Clinical Trials Group P1045 Team (2010) Total body and spinal bone mineral density across Tanner stage in perinatally HIV-infected and uninfected children and youth in PACTG 1045. AIDS 24:687-696.

Kamboj S, Saini V, and Bala S (2014) Formulation and characterization of drug loaded nonionic surfactant vesicles (niosomes) for oral bioavailability enhancement. Sci World J 2014:959741.

Kearney BP, Flaherty JF, and Shah J (2004) Tenofovir disoproxil fumarate: clinical pharmacology and pharmacokinetics. Clin Pharmacokinet 43:595-612.

Kearney BP and Mathias A (2009) Lack of effect of tenofovir disoproxil fumarate on pharmacokinetics of hormonal contraceptives. Pharmacotherapy 29:924-929.

King JR, Yogev R, Jean-Philippe P, Graham B, Wiznia A, Britto P, Carey V, Hazra R, and Acosta EP; P1058 Protocol Team (2011) Steady-state pharmacokinetics of tenofovir-based regimens in HIV-infected pediatric patients. Antimicrob Agents Chemother 55:4290-4294.

Kohler JJ, Hosseini SH, Hoying-Brandt A, Green E, Johnson DM, Russ R, Tran D, Raper CM, Santoianni R, and Lewis W (2009) Tenofovir renal toxicity targets mitochondria of renal proximal tubules. Lab Invest 89:513-519.

Laurinavicius A, Hurwitz S, and Rennke HG (1999) Collapsing glomerulopathy in HIV and non-HIV patients: a clinicopathological and follow-up study. Kidney Int $\mathbf{5 6}: 2203-2213$

Lebrecht D, Venhoff AC, Kirschner J, Wiech T, Venhoff N, and Walker UA (2009) Mitochondrial tubulopathy in tenofovir disoproxil fumarate-treated rats. J Acquir Immune Defic Syndr 51:258-263.

Lee WA, He GX, Eisenberg E, Cihlar T, Swaminathan S, Mulato A, and Cundy KC (2005) Selective intracellular activation of a novel prodrug of the human immunodeficiency virus reverse transcriptase inhibitor tenofovir leads to preferential distribution and accumulation in lymphatic tissue. Antimicrob Agents Chemother 49:1898-1906.

Lepist EI, Phan TK, Roy A, Tong L, Maclennan K, Murray B, and Ray AS (2012) Cobicistat boosts the intestinal absorption of transport substrates, including HIV protease inhibitors and GS-7340, in vitro. Antimicrob Agents Chemother 56: $5409-5413$ 
Marrazzo JM, Ramjee G, Richardson BA, Gomez K, Mgodi N, Nair G, Palanee T, Nakabiito C, van der Straten A, Noguchi L, et al.; VOICE Study Team (2015) Tenofovir-based preexposure prophylaxis for HIV infection among African women. $N$ Engl J Med 372:509-518.

Mathias AA, Hinkle J, Menning M, Hui J, Kaul S, and Kearney BP; Efavirenz/ Emtricitabine/Tenofovir Disoproxil Fumarate Single-Tablet Regimen Development Team (2007) Bioequivalence of efavirenz/emtricitabine/tenofovir disoproxil fumarate single-tablet regimen. J Acquir Immune Defic Syndr 46:167-173.

Mathias A, Menning M, Wiser L, Wei X, Dave A, Chuck S, and Kearney BP (2012) Bioequivalence of the emtricitabine/rilpivirine/tenofovir disoproxil fumarate single tablet regimen. J Bioequiv Avilab 4:100-105.

Miller MD, Margot NA, Hertogs K, Larder B, and Miller V (2001) Antiviral activity of tenofovir (PMPA) against nucleoside-resistant clinical HIV samples. Nucleosides Nucleotides Nucleic Acids 20:1025-1028.

Mills A, Arribas JR, Andrade-Villanueva J, DiPerri G, Van Lunzen J, Koenig E, Elion R, Cavassini M, Madruga JV, Brunetta J, et al; GS-US-292-0109 Team (2016) Switching from tenofovir disoproxil fumarate to tenofovir alafenamide in antiretroviral regimens for virologically suppressed adults with HIV-1 infection: a randomised, active-controlled, multicentre, open-label, phase 3, non-inferiority study. Lancet Infect Dis 16:43-52.

Mirochnick M, Taha T, Kreitchmann R, Nielsen-Saines K, Kumwenda N, Joao E Pinto J, Santos B, Parsons T, Kearney B, et al.; HPTN 057 Protocol Team (2014) Pharmacokinetics and safety of tenofovir in HIV-infected women during labor and their infants during the first week of life. J Acquir Immune Defic Syndr 65 : $33-41$.

Molina JM, Cahn P, Grinsztejn B, Lazzarin A, Mills A, Saag M, Supparatpinyo K, Walmsley S, Crauwels H, Rimsky LT, et al.; ECHO Study Group (2011) Rilpivirine versus efavirenz with tenofovir and emtricitabine in treatment-naive adults in fected with HIV-1 (ECHO): a phase 3 randomised double-blind active-controlled trial. Lancet 378:238-246.

Nomura M, Motohashi H, Sekine H, Katsura T, and Inui K (2012) Developmental expression of renal organic anion transporters in rat kidney and its effect on rena secretion of phenolsulfonphthalein. Am J Physiol Renal Physiol 302:F1640-F1649.

O'Brien KO, Razavi M, Henderson RA, Caballero B, and Ellis KJ (2001) Bone mineral content in girls perinatally infected with HIV. Am J Clin Nutr 73:821-826.

Polli JW, Jarrett JL, Studenberg SD, Humphreys JE, Dennis SW, Brouwer KR, and Woolley JL (1999) Role of P-glycoprotein on the CNS disposition of amprenavir (141W94), an HIV protease inhibitor. Pharm Res 16:1206-1212.

Pozniak A, Arribas JR, Gathe J, Gupta SK, Post FA, Bloch M, Avihingsanon A Crofoot G, Benson P, Lichtenstein K, et al.; GS-US-292-0112 Study Team (2016) Switching to tenofovir alafenamide, coformulated with elvitegravir, cobicistat, and emtricitabine, in HIV-infected patients with renal impairment: 48-week results from a single-arm, multicenter, open-label phase 3 study. J Acquir Immune Defic Syndr 71:530-537.

Puthanakit T, Saksawad R, Bunupuradah T, Wittawatmongkol O, Chuanjaroen T, Ubolyam S, Chaiwatanarat T, Nakavachara P, Maleesatharn A, and Chokephaibulkit K (2012) Prevalence and risk factors of low bone mineral density among perinatally HIV-infected Thai adolescents receiving antiretroviral therapy. J Acquir Immune Defic Syndr 61:477-483.

Quesada PR, Esteban LL, García JR, Sánchez RV, García TM, Alonso-Vega GG, and Ferrández JS (2015) Incidence and risk factors for tenofovir-associated renal toxicity in HIV-infected patients. Int J Clin Pharm 37:865-872.

Ravi PR, Joseph S, Avula USR, and Anthireddy S (2015) A simple liquid chromatographic method for the determination of tenofovir in rat plasma and its application to pharmacokinetic studies. Acta Chromatogr 27:597-612.

Ray AS, Cihlar T, Robinson KL, Tong L, Vela JE, Fuller MD, Wieman LM, Eisenberg EJ, and Rhodes GR (2006) Mechanism of active renal tubular efflux of tenofovir. Antimicrob Agents Chemother 50:3297-3304.

Ray PE (2012) HIV-associated nephropathy: a diagnosis in evolution. Nephrol Dial Transplant 27:3969-3972.

Robbins BL, Srinivas RV, Kim C, Bischofberger N, and Fridland A (1998) Antihuman immunodeficiency virus activity and cellular metabolism of a potential prodrug of the acyclic nucleoside phosphonate 9-R-(2-phosphonomethoxypropyl)adenine (PMPA), Bis(isopropyloxymethylcarbonyl)PMPA. Antimicrob Agents Che mother 42:612-617.

Saag MS (2006) Emtricitabine, a new antiretroviral agent with activity against HIV and hepatitis B virus. Clin Infect Dis 42:126-131.

Sax PE, Wohl D, Yin MT, Post F, DeJesus E, Saag M, Pozniak A, Thompson M Podzamczer D, Molina JM, et al.; GS-US-292-0104/0111 Study Team (2015) Tenofovir alafenamide versus tenofovir disoproxil fumarate, coformulated with elvitegravir, cobicistat, and emtricitabine, for initial treatment of HIV-1 infection: two randomised, double-blind, phase 3, non-inferiority trials. Lancet $\mathbf{3 8 5}$ $2606-2615$

Schtscherbyna A, Pinheiro MF, Mendonça LM, Gouveia C, Luiz RR, Machado ES, and Farias ML (2012) Factors associated with low bone mineral density in a
Brazilian cohort of vertically HIV-infected adolescents. Int $J$ Infect Dis 16: e872-e878.

Schwartz EJ and Klotman PE (1998) Pathogenesis of human immunodeficiency virus (HIV)-associated nephropathy. Semin Nephrol 18:436-445.

Shailender J, Ravi PR, Saha P, and Myneni S (2017) Oral pharmacokinetic interaction of ester rich fruit juices and pharmaceutical excipients with tenofovir disoproxil fumarate in male Wistar rats. Xenobiotica 12:1-8.

Shaw JP, Sueoko CM, Oliyai R, Lee WA, Arimilli MN, Kim CU, and Cundy KC (1997) Metabolism and pharmacokinetics of novel oral prodrugs of 9-[(R)-2 (phosphonomethoxy)propyl]adenine (PMPA) in dogs. Pharm Res 14:1824-1829.

Shen Z, Fahey JV, Bodwell JE, Rodriguez-Garcia M, Kashuba AD, and Wira CR (2014) Sex hormones regulate tenofovir-diphosphate in female reproductive tract cells in culture. PLoS One 9:e100863.

Sherman EM, Worley MV, Unger NR, Gauthier TP, and Schafer JJ (2015) Cobicistat: review of a pharmacokinetic enhancer for HIV infection. Clin Ther 37:1876-1893.

Shiomi M, Matsuki S, Ikeda A, Ishikawa T, Nishino N, Kimura M, and Irie S (2014) Effects of a protein-rich drink or a standard meal on the pharmacokinetics of elvitegravir, cobicistat, emtricitabine and tenofovir in healthy Japanese male subjects: a randomized, three-way crossover study. J Clin Pharmacol 54:640-648.

Spinks CB, Zidan AS, Khan MA, Habib MJ, and Faustino PJ (2017) Pharmaceutical characterization of novel tenofovir liposomal formulations for enhanced oral drug delivery: in vitro pharmaceutics and Caco-2 permeability investigations. Clin Pharmacol 9:29-38.

Squires K, Pozniak AL, Pierone G, Jr, Steinhart CR, Berger D, Bellos NC, Becker SL, Wulfsohn M, Miller MD, Toole JJ, et al. Study 907 Team (2003) Tenofovir disoproxil fumarate in nucleoside-resistant HIV-1 infection: a randomized trial. Ann Intern Med 139:313-320.

Tong L, Phan TK, Robinson KL, Babusis D, Strab R, Bhoopathy S, Hidalgo IJ, Rhodes GR, and Ray AS (2007) Effects of human immunodeficiency virus protease inhibitors on the intestinal absorption of tenofovir disoproxil fumarate in vitro. Antimicrob Agents Chemother 51:3498-3504.

van der Sandt IC, Vos CM, Nabulsi L, Blom-Roosemalen MC, Voorwinden HH, de Boer AG, and Breimer DD (2001) Assessment of active transport of HIV protease inhibitors in various cell lines and the in vitro blood-brain barrier. AIDS 15:483-491.

Van Gelder J, Annaert P, Naesens L, De Clercq E, Van den Mooter G, Kinget R and Augustijns P (1999) Inhibition of intestinal metabolism of the antiviral ester prodrug bis(POC)-PMPA by nature-identical fruit extracts as a strategy to enhance its oral absorption: an in vitro study. Pharm Res 16:1035-1040.

van Gelder J, Deferme S, Naesens L, De Clercq E, van den Mooter G, Kinget R, and Augustijns P (2002) Intestinal absorption enhancement of the ester prodrug tenofovir disoproxil fumarate through modulation of the biochemical barrier by defined ester mixtures. Drug Metab Dispos 30:924-930.

Verhelst D, Monge M, Meynard JL, Fouqueray B, Mougenot B, Girard PM, Ronco P, and Rossert J (2002) Fanconi syndrome and renal failure induced by tenofovir: a first case report. Am J Kidney Dis 40:1331-1333.

Washington CB, Duran GE, Man MC, Sikic BI, and Blaschke TF (1998) Interaction of anti-HIV protease inhibitors with the multidrug transporter P-glycoprotein (P-gp) in human cultured cells. J Acquir Immune Defic Syndr Hum Retrovirol 19:203-209.

Wira CR and Fahey JV (2008) A new strategy to understand how HIV infects women: identification of a window of vulnerability during the menstrual cycle. AIDS 22: 1909-1917.

Wohl D, Oka S, Clumeck N, Clarke A, Brinson C, Stephens J, Tashima K, Arribas JR, Rashbaum B, Cheret A, et al.; GS-US-2,92-01040111 and Study Team (2016) Brief report: a randomized, double-blind comparison of tenofovir alafenamide versus tenofovir disoproxil fumarate, each coformulated with elvitegravir, cobicistat, and emtricitabine for initial HIV-1 treatment: week 96 results. J Acquir Immune Defic Syndr 72:58-64.

Woodward CL, Hall AM, Williams IG, Madge S, Copas A, Nair D, Edwards SG, Johnson MA, and Connolly JO (2009) Tenofovir-associated renal and bone toxicity. HIV Med 10:482-487.

Wyatt CM, Klotman PE, and D'Agati VD (2008) HIV-associated nephropathy: clinical presentation, pathology, and epidemiology in the era of antiretroviral therapy. Semin Nephrol 28:513-522.

Wyatt CM, Morgello S, Katz-Malamed R, Wei C, Klotman ME, Klotman PE, and D'Agati VD (2009) The spectrum of kidney disease in patients with AIDS in the era of antiretroviral therapy. Kidney Int 75:428-434.

Yuan LC, Dahl TC, and Oliyai R (2001) Degradation kinetics of oxycarbonyloxymethyl prodrugs of phosphonates in solution. Pharm Res 18:234-237.

Address correspondence to: Dr. Monica A. Valentovic, 1 Marshall Drive, Department of Biomedical Sciences, Room 435 G, Byrd Biotech Science Building, Joan C. Edwards School of Medicine, Marshall University, Huntington, WV 25755-9308. E-mail: valentov@marshall.edu 